\title{
Artigo
}

\section{O congado vai para a escola e a escola vai para o congado}

El congado va a la escuela y la escuela va al congado

The congado goes to school and the school goes to congado

Marcus Vinícius Fonseca

Fabiana Siqueira Silva

Universidade Federal de Ouro Preto, Brasil

Recebido em: 30/08/2020

Aceito em: 28/10/2020

\section{Resumo}

Nesse artigo apresentamos aspectos ligados à uma experiência singular envolvendo o congado e a escola que ocorre na Associação dos Pais e Amigos dos Excepcionais de Ouro Preto (APAE-OP), onde surgiu um grupo de congado como parte de um projeto pedagógico e se firmou como elemento de culto à Nossa Senhora do Rosário. Analisamos essa experiência através de um estudo de caso que procurou caracterizar o congado em Ouro Preto, sua emergência dentro da escola e seus desdobramentos pedagógicos. Procuramos destacar a singularidade dessa experiência demonstrando como ela está relacionada com a dinâmica de uma cidade onde a cultura negra se manifesta com intensidade.

Palavras-chave: Congado. Cultura Negra. Educação Especial.

\section{Resumen}

En este artículo presentamos aspectos relacionados con una experiencia única que involucra al congado y la escuela. La experiencia ocurre en la Asociación de Padres y Amigos de los Excepicionales de los Ouro Preto, donde un grupo de congados surgió como parte de un proyecto pedagógico y se estableció como un elemento de culto a Nossa Senhora do Rosário. Analizamos esta experiencia a través de un estudio de caso que buscaba caracterizar el congado en Ouro Preto, su surgimiento dentro de la escuela y sus desarrollos pedagógicos. Buscamos resaltar la singularidad de esta experiencia 
demostrando cómo se relaciona con la dinámica de una ciudad donde la cultura negra se manifiesta con intensidad.

Palabras clave: Congado. Cultura Negra. Educación Especial.

\section{Abstract}

In this article we present aspects that are linked to a unique experience involving the congado and the school. The experience takes place at the Ouro Preto Association of Parents and Friends of the Exceptional Children, where a group of congado emerged as part of a pedagogical project and established itself as an element of worship to Nossa Senhora do Rosário. We analyzed this experience through a case study that sought to characterize the congado in Ouro Preto, its emergence within the school and its pedagogical developments. We seek to highlight the uniqueness of this experience by demonstrating how it is related to the dynamics of a city where black culture manifests itself with intensity.

Keywords: Congado. Black Culture. Special Education.

\section{O congado em Minas Gerais e na cidade de Ouro Preto}

Esse artigo tem como objetivo apresentar diferentes aspectos de uma experiência que ocorre em uma escola de Ouro Preto onde houve a incorporação do congado em meio às práticas pedagógicas de uma escola de educação especial. Para demonstrar esse processo de incorporação realizamos uma análise que procura demonstrar a força que tem o congado dentro da cidade, pois é isso que justifica sua capacidade de impor elementos da cultura negra em meio às prática educativas desenvolvidas na escola da Associação de Pais e Amigos dos Excepcionais de Ouro Preto (APAE-OP).

O congado se constitui como uma referência da cultura e da religiosidade da população negra no Brasil. Seu processo de surgimento e elaboração se estabeleceu como uma forma dos negros cultuarem suas origens africanas por meio de festejos que rememoram sua luta, sua fé e seus sofrimentos durante o período do cativeiro. Ele pode ser entendido como um rito religioso que se estrutura através do culto fervoroso à Nossa Senhora do Rosário, santa que foi concebida como uma entidade que concorreu para amenizar os sofrimentos dos negros quando estes estavam submetidos aos desmandos da escravidão.

Portanto, essa manifestação religiosa se estrutura como uma das mais fortes tradições culturais brasileiras na qual a devoção a Nossa Senhora do Rosário se sustenta através de narrativas míticas que rememoram a forte ligação que se estabeleceu entre os negros e a santa.

As narrativas que sustentam o culto possuem diferentes variações. Algumas indicam que a santa foi vista por negros escravizados em uma gruta, ou em um rio, mas, a que prevalece é aquela que registra que esse encontro se deu no mar. A melhor forma de perceber a força dessa narrativa é através da fala dos próprios congadeiros, como

Fonseca, M. V., Silva, F. S. O congado vai para a escola e a escola vai para o congado 2 
aquela que foi coletada por Gomes e Pereira (2003, p. 45), a partir do registro oral do congadeiro Geraldo Arthur Camilo', que foi Rei Congo do Estado de Minas Gerais:

Ninguém tinha liberdade, que era tempo de escravidão. O povo era só trabaiá. Então Nossa Senhora apareceu lá nas água. Os rico foi pra tirá ela, com banda de música, e tal; ela num quis. Quando o padre foi celebrá missa, falano palavra, ela só mexeu um mucadim, mas parô. Por que Nossa Senhora não queria luxo. E foro aqueles fazendeiro com muito luxo, coisa boa pra pô ela ali dentro, aquele luxo. Ela parô. Eles pelejô, pelejô, ela ficô parada lá na água. Eles então vei embora.

Conforme o relato do congadeiro Geraldo Arthur Camilo, os donos de escravos chamaram um padre para retirar a santa do mar. $O$ padre se serviu de rezas e cantos, mas a santa permaneceu no mesmo lugar. Ela não queria luxo e nem tampouco a devoção dos poderosos, pois, não havia vindo em socorro a eles. Diante da ineficiência dos esforços movidos pelo padre os negros escravizados pediram permissão aos seus senhores para tentar retirar a santa da água. Na ocasião obtiveram a seguinte resposta de seus senhores:

- Ah, nego, ocês tá quereno é coro! Pois se nós foi lá, com uma banda de música, primeiro nós levô o padre, fomo com tudo tão organizado e ela num saiu... agora ocês é que vai!...

E o escravo disse:

- Não, nós vamo só fazê oração lá. Se nós recebe a graça, muito bem; se nós num recebe, nós volta pra sanzala e vamo trabaiá.

E foi ele disse:

- Cês vai. Se ela num vié, caboco cês perdeu a vez, cês vai entrá é no coro. (Gomes \& Pereira, 2003, p. 46)

Com a permissão dos senhores os escravizados cantaram em língua africana, dançaram e rezaram ao som dos tambores. Diante dessa manifestação a imagem de Nossa Senhora do Rosário começou a se mover em direção à praia.

Ah, os branco achô ruim! Quando ela parô na berada, eles tiraro ela. Com a banda de música, foguete, essas coisa. Tudo de novo. Ela ficô quetinha: pegaro ela, levô. Fizero lá uma capelinha, pôs ela lá dentro. Os nego, esses já foi ficano pra trás e acabô ino tudo pra sanzala deles.

Quando foi no oto dia, eles abriro lá a capela, cadê eça? Tinha voltado pro mesmo lugá.

Voltarô tudo pra vê: a santinha lá no meio do mar, parada.

Os negô armô a capelinha deles - cá no ponto de pobre, née - pé de chão, otros de precata, cantano, ela veio vino, eles arranjo seu andô deles. Tudo no ponto de pobre - pôs ela no lugar lá liga de nego humilde - e ela ficô. Aí eles fizero a igrejinha dela e ela nunca que voltô. (Gomes \& Pereira, 2003, p.47)

Os cantos de lamúria, devoção e fé dos negros fizeram a santa se movimentar para a praia. Os senhores, então, levaram a santa para uma capela e excluíram os negros

\footnotetext{
I Geraldo Arthur Camilo morreu em 2004 e era membro dos Arturos, em Contagem/MG, uma das mais tradicionais comunidades negras de Minas, onde a festa do Rosário é um evento de grande importância. Em 1986, ele foi celebrado o primeiro Rei Congo de Minas Gerais.
}

3 - Linhas Críticas, Brasília, DF, v. 26 (2020), p. 3-16 
escravizados do rito de celebração. Em represália a essa atitude a santa voltou para o mar. Os negros foram novamente resgatá-la e ao ser resgatada pela segunda vez a santa foi levada para a senzala, onde seu altar era um tambor feito de madeira. Diante dele, seus devotos louvaram e pediram proteção.

De acordo com os congadeiros de tanto implorar proteção a Deus os negros foram ouvidos e Nossa Senhora foi enviada para protegê-los. Ao ver e ouvir suas histórias de sofrimentos Nossa Senhora do Rosário chorou. No local em que suas lágrimas caíram nasceu uma plantação que deu pequenos frutos denominados de contas de lágrimas. Com a semente desse fruto foi produzido o primeiro rosário, ou terço de contas, utilizado pelos congadeiros na realização de suas orações (Alves, 2017).

A presença de Nossa Senhora do Rosário é uma referência universal da igreja católica que, durante o período da escravidão, foi apropriada e ressignificada dentro da prática do congado. Essa herança é conservada por meio de festas em que os congadeiros vivem e preservam sua cultura, mantendo viva a devoção a santa.

O congado foi disseminado em todo país e está presente em vários estados brasileiros. $\bigcirc$ estado de Minas Gerais é visto como uma das regiões com maior presença dessa manifestação religiosa. Nele, destaca-se a cidade de Ouro Preto que se caracteriza por ser um local onde encontramos uma das mais fortes manifestações da cultura congadeira. Essa pode ser definida como um conjunto de atividades que se organiza em torno do culto à Nossa Senhora do Rosário através da coroação de reis, cantos, danças e cortejos que estruturam uma celebração a partir da vivência de tradições africanas, que criam um elo intangível de resistência e devoção

A origem do congado em Ouro Preto2 está ligada ao movimento de constituição das irmandades negras e é datado de 1718, mais especificamente com o surgimento da Irmandade de Nossa Senhora do Rosário que estava vinculada à Matriz de Nossa Senhora da Conceição que, naquela época, reunia indivíduos negros e brancos. No entanto, como era comum no escravismo brasileiro, estruturado fundamentalmente por uma dominação racial, ocorreu dentro da irmandade uma ruptura entre negros e brancos dando origem a uma irmandade específica: a Irmandade de Nossa Senhora do Rosário dos Pretos. Foi em torno dessa irmandade, que surgiu e se estabeleceu o congado, como parte do processo de afirmação da população negra na cidade (Borges, 2005).

Em Ouro Preto, o congado tornou-se uma instituição centenária que, ainda hoje, mantém viva sua força e tradição. Isso pode ser visto através do Congado de Nossa Senhora do Rosário e Santa Efigênia, do distrito de Miguel Burnier, que tem mais de 150 anos de existência. Além desse, Ouro Preto conta ainda com outras cinco guardas de

2 Ouro Preto foi a mais importante cidade mineira que surgiu durante o ciclo do ouro. Sua origem remonta a um arraial que em 1711 foi promovido à vila recebendo o nome de Vila Rica. Em 1720, Vila Rica tornouse sua capital de Minas, em 1823, foi promovida à condição de cidade passando a ser designada como Ouro Preto.

Fonseca, M. V., Silva, F. S. O congado vai para a escola e a escola vai para o congado 4 
congado que são responsáveis por uma intensa movimentação no calendário da cidade, ao longo de todo o ano. São elas: o Congado de Nossa Senhora do Rosário e Santa Efigênia, do bairro do Alto da Cruz, o Congado de Nossa senhora do Rosário e São Benedito, do distrito de Santo Antônio do Salto, a Guarda de Nossa Senhora Aparecida, a Guarda de Moçambique de Nossa Senhora do Rosário e Santa Efigênia e o Congado de Nossa Senhora do Rosário e Nossa Senhora das Graças, da Associação de Pais e Amigos dos Excepcionais (APAE) - que é objeto da análise que empreendemos nesse artigo.

Ouro Preto também se revela como um polo de atração para guardas de congado de diferentes regiões de Minas e do Brasil, que a consideram como uma cidade que está na própria origem dessa manifestação religiosa. Isso se deve, sobretudo, à lendária figura de Chico Rei, ex-escravo que é considerado como um dos fundadores do culto a Nossa Senhora do Rosário.

Segundo as narrativas dos congadeiros, Chico Rei era um rei africano que foi escravizado e trazido para Ouro Preto, no século XVIII. Ele trabalhou nas minas de ouro da cidade por longos anos e conseguiu fazer um pecúlio que the permitiu comprar sua liberdade. Na condição de homem livre tornou-se proprietário de uma mina de ouro através da qual organizou uma sociedade de ajuda mútua que foi responsável pela compra da liberdade de vários africanos escravizados. Atribui-se a Chico Rei uma destacada atuação na Irmandade de Nossa Senhora do Rosário dos Pretos tendo sido ele o primeiro Rei Congo a fazer um termo de congado assumindo, assim, o papel de disseminador dessa prática no Brasil (Martins, 1991).

Em Ouro Preto o congado se constitui como uma manifestação cultural que é vivenciada com intensidade. Isso não o isenta de um enfrentamento com as manifestações de preconceito e desqualificação dentro da dinâmica da cidade que, na verdade, lida de forma tensa com as manifestações culturais ligadas à comunidade negra. Portanto, é a partir de uma lógica que se manifesta através da força e da resistência que o congado se afirma cotidianamente na cidade.

A maior prova disso podemos encontrar em uma experiência que foi capaz de introduzir essa manifestação cultural em uma instituição de ensino vinculada à Associação de Pais e Amigos dos Excepcionais (APAE), dando origem a uma experiência singular dentro da educação e mesmo na dinâmica tradicional do surgimento das guardas de congado.

A organização dos grupos de congado geralmente está vinculada às manifestações religiosas de comunidades tradicionais, ou seja, desconhecemos um grupo que tenha tido sua origem fora dessa lógica. Nesse sentido, a experiência que encontramos em Ouro Preto através da Associação de Pais e Amigos dos Excepcionais (APAE) é absolutamente singular, pois trata-se de um grupo de congado que teve sua origem em uma instituição educacional. 
No Brasil, há uma tensão no processo de incorporação da cultura negra como elemento constitutivo das práticas pedagógicas. Isso se torna evidente quando consideramos a aprovação da Lei 10.639/2003 que estabeleceu parâmetros normativos para obrigar as instituições de ensino a modificar a postura etnocêntrica que tradicionalmente as orientam tornando obrigatório o ensino de história e cultura afro-brasileira.

A resistência à cultura negra que encontramos no contexto escolar é um fenômeno que tem sua origem na própria emergência da escola que, no Brasil, sempre foi entendida como uma instituição formativa cujo parâmetro sempre foi a cultura europeia. Nesse sentido, as manifestações culturais produzidas pela população negra geralmente foram entendidas como elementos externos e estranhos ao contexto escolar. Muitas vezes foram tomadas como algo que deveria ser combatido em nome de concepções eurocêntricas de cultura, civilização, modernidade ou qualquer outro dispositivo mobilizado historicamente para legitimar a produção do aparato escolar como elemento regulador da sociedade.

Este artigo tem como objetivo demonstrar a força do congado na cidade de Ouro Preto através da análise de uma experiência que levou a sua incorporação a uma escola na qual surgiu a guarda de Congado de Nossa Senhora do Rosário e Nossa Senhora das Graças. Trata-se de uma guarda que existe desde o ano de 2002 e é reconhecida pelos grupos tradicionais da cidade, mesmo tendo a sua origem em uma atividade pedagógica que ocorrev em uma instituição de ensino.

Para elaboração da análise recorremos aos procedimentos que caracterizam um estudo de caso que é a forma mais eficaz de conduzir uma problematização daquilo que tem valor em si mesmo (Lüdke \& André, 1986). Na condução desse estudo de caso recorremos a vários materiais de pesquisa que foram capazes de revelar diferentes dimensões da experiência do Congado de Nossa Senhora do Rosário e Nossa Senhora das Graças, que está vinculado a escola da Associação de Pais e Amigos dos Excepcionais de Ouro Preto (APAE-OP). Entre esses, destaca-se a análise de documentos relativos ao congado e a instituição na qual ele está inserido; entrevistas com professores e coordenadores pedagógicos da escola; grupo focal com alunos que se encontravam vinculados ao congado da escola; e a observação de diferentes atividades desenvolvidas pelo grupo de congado dentro e fora do espaço escolar, no período entre os anos de 2014 a 2016.

Existem várias dimensões interessantes em relação a essa experiência em que o congado foi incorporado ao contexto escolar, inclusive tensões ligadas à religiosidade da família dos alunos e a organização pedagógica da escola. No entanto, nesse artigo elaboramos uma abordagem que confere destaque ao processo de emergência da guarda de congado dentro da escola e seu significado dentro da cultura congadeira que se manifesta na cidade de Ouro Preto.

Fonseca, M. V., Silva, F. S. O congado vai para a escola e a escola vai para o congado 6 


\section{O Surgimento do Congado na Escola da APAE-OP}

No Brasil, as Associações de Pais e Amigos dos Excepcionais (APAE) se constituíram a partir dos anos de 1950 como instituições voltadas para o atendimento de crianças e jovens com algum tipo deficiência mental. Isso se tornou necessário diante da inexistência de políticas e serviços educacionais de natureza pública destinados a esse grupo. A inexistência de políticas educacionais para pessoas com deficiências fez com que o movimento das Associações de Pais e Amigos dos Excepcionais (APAE) se expandisse como uma iniciativa privada destinada a oferecer assistência a alunos com deficiência, e também auxílio a seus familiares (Mazzota, 1996). Essas instituições se espalharam por todo o território brasileiro. Segundo dados da Federação Nacional das Associações de Pais e Amigos dos Excepcionais (FENAPAES), até o ano de 2017, existiam 2.159 escolas compondo aquilo que pode ser chamado de o maior movimento de educação de pessoas com deficiência do mundo (FENAPAES, 2017).

Entre as inúmeras associações criadas em todo Brasil encontra-se a Associação de Pais e Amigos dos Excepcionais de Ouro Preto (APAE-OP). A APAE-OP é mantenedora da Escola de Educação Especial Dr. Hélio Harmendani, instituição educacional que conta com a colaboração da prefeitura municipal de Ouro Preto e de outros órgãos que auxiliam sua manutenção e funcionamento.

O surgimento da APAE-OP ocorreu, em 1982, como desdobramento de discussões realizadas entre pessoas da comunidade ouro-pretana, profissionais da saúde, professores e pais de crianças e adolescentes com deficiência. De acordo com a Ata de Assembleia de Constituição da APAE-OP sua fundação ocorreu no salão de reuniões da Escola Técnica de Ouro Preto, atualmente Instituto Federal Minas Gerais (APAE-OP, 1982). O farmacêutico Hélio Harmendani ficou encarregado de conduzir os trabalhos sendo também integrante da comissão responsável pela elaboração do estatuto que regeria a instituição. Por esse motivo foi posteriormente homenageado e teve seu nome intitulando a escola da APAE-OP.

Inicialmente sua estrutura e seu quadro profissional eram bem restritos contado somente com duas professoras especializadas e com quatro voluntários. Em 1984, por meio de uma lei municipal, a APAE-OP foi denominada como uma instituição de utilidade pública. Após dez anos de sua fundação se filiou à Federação Nacional das Associações de Pais e Amigos dos Excepcionais (FENAPAES) passando a seguir as determinações que orientam essa federação. Em 2001, foi reconhecida como instituição de utilidade pública em nível federal.

Sua legitimação em nível municipal, estadual e federal foi fundamental para seu reconhecimento junto à comunidade local possibilitando, entre outras coisas, o acesso a recursos públicos e sua efetivação dentro do sistema educacional da cidade. 
No que se refere aos preceitos institucionais a APAE-OP segue a mesma perspectiva das APAEs de todo o país assumindo, segundo seu estatuto, a seguinte missão: promover e articular ações de defesa de direitos e prevenção, orientações, prestação de serviços, apoio à família, direcionadas à melhoria da qualidade de vida da pessoa com deficiência e à construção de uma sociedade justa e solidária (APAE-OP, 2012).

O Projeto Político Pedagógico da escola da APAE-OP define que a instituição tem o compromisso de oferecer a seus alunos um ensino que propicie uma aprendizagem efetiva, que desperte o seu interesse na busca por novos saberes. A instituição tem como um de seus pressupostos o tratamento da pessoa com deficiência como um ser humano dotado de sentimentos, emoções e elaborações mentais. Assim, a escola da APAE-OP afirma que se atém às particularidades do indivíduo, sendo a deficiência entendida como uma de suas múltiplas características, e não como a única configuração possível de sua individualidade (APAE-OP, 2008).

Em 2014, a instituição contava com 215 alunos com idades variadas. Esses possuíam diferentes tipos de deficiências: intelectual, atraso do desenvolvimento neuropsicomotor, distúrbio de equilíbrio, alterações de coordenação motora, diminuição da força muscular, paralisia cerebral, autismo, distúrbio de interação social, traumatismo crânio encefálico, AVC (Acidente Vascular Cerebral), síndrome de Down e outras síndromes.

No atendimento a esse público a escola da APAE-OP procura cumprir a legislação educacional que trata da inclusão das pessoas com deficiência. Na legislação brasileira a educação especial foi definida como uma modalidade de ensino, assim a escola da APAE-OP tomou a iniciativa de adaptar-se a essas normas configurando, desde 2011, a sua escola como um serviço regular. Dentro disso, ocorre um processo de flexibilização do currículo que se organiza como o de uma escola convencional, mas, confere destaque a procedimentos pedagógicos que são estruturados a partir de oficinas, projetos e uma variedade de atividades extracurriculares que procuram considerar as especificidades do seu alunado.

Essas atividades levam em conta o perfil dos alunos através de elementos que são entendidos como essenciais em seu processo de formação, entres eles destacam-se o desenvolvimento de habilidades tecnológicas, artes, linguagens, cultura e conhecimentos ligados à saúde. Foi em meio às atividades pedagógicas que compõem o processo de flexibilização curricular que o congado se estabeleceu dentro da escola da APAE-OP.

No ano de 2002, houve na escola um evento cultural que tinha como objetivo a comemoração da Semana do Excepcional. Nesse evento os alunos deveriam preparar atividades a serem apresentadas à comunidade escolar destacando a cultura da cidade de Ouro Preto. Em função de sua importância dentro da vida da cidade o congado foi escolhido como uma das atividades que seriam apresentadas na Semana do Excepcional.

Fonseca, M. V., Silva, F. S. O congado vai para a escola e a escola vai para o congado 8 
A educadora responsável pela organização dessa atividade - professora Silvânia buscou informações sobre o tema com os congadeiros da cidade e as repassou aos alunos. Assim, um grupo de alunos foi organizado como uma pequena guarda, representando de maneira teatral os cantos e as danças do congado como forma de demonstração e valorização da cultura local.

A apresentação do grupo foi muito positiva entre os alunos envolvidos com a atividade e também junto à comunidade escolar. Depois desse evento começaram a surgir convites para apresentações do grupo em várias instituições, em Ouro Preto e nas cidades vizinhas. Essas apresentações aconteciam de forma lúdica, ou seja, sem a incorporação efetiva das manifestações religiosas que caracterizam o congado e sua devoção a Nossa Senhora do Rosário.

As apresentações foram ganhando proporções cada vez maiores surgindo, então, a necessidade de institucionalização do congado dentro da proposta pedagógica da escola da APAE-OP. Assim, o congado começou seu processo de institucionalização passando a ser registrado formalmente como um projeto pedagógico dentro da estrutura de flexibilização do currículo da instituição. Algo semelhante ao que ocorreu com outras iniciativas que também obtiveram o mesmo reconhecimento como o Projeto Ser APAE É Ser Comunidade, Projeto Inclusão Digital, Projeto Mãos a Arte, Projeto Artes Cênicas, Projeto Coral de Libras, Projeto Verde, Verdura, Horta na Escola.

De acordo com a professora Silvânia tudo foi acontecendo de forma natural, sem perspectivas previamente estabelecidas. O grupo foi ganhando visibilidade. Além de apresentações em escolas e empresas, passou a estar presente também em festas religiosas da cidade. Dessa forma, o congado colocou em evidência a escola da APAEOP e as ações da própria professora que se tornou, por sua vez, objeto de cobranças do segmento composto pelos membros mais tradicionais do congado de Ouro Preto. Esses demonstraram uma preocupação com a espetacularização dos ritos do congado e passaram a questionar o grupo em relação ao significado religioso de devoção a Nossa Senhora do Rosário.

Essa cobrança determinou que a professora se aproximasse da tradição e fizesse sua própria iniciação dentro das práticas religiosas do congado. Segundo seu depoimento, isso ocorreu alguns anos depois do surgimento da guarda quando ela foi interpelada da seguinte forma por uma das pessoas ligadas à tradição congadeira: você tem duas opções, ou você continua sendo para folclórico, só mesmo para fazer essas apresentações, continue nessa atividade educativa, ou então você vai se tornar de tradição.

Os representantes do congado na cidade cobraram e impuseram que a professora se posicionasse diante da tradição. Essa cobrança determinou que a professora Silvania mobilizasse as experiências pessoais que tinha com o congado que, segundo ela, remontavam à sua infância. Com isso, buscou a formação que a transformou na capitã

9 - Linhas Críticas, Brasília, DF, v. 26 (2020), p. 9-16 
do Congado da APAE-OP, assim a guarda passou a incorporar os diferentes elementos que regem à tradição. A guarda incorporou de forma efetiva os ritos religiosos e passou a se relacionar com as demais guardas da cidade no movimento de reverência à figura de Nossa Senhora do Rosário incorporando os saberes vinculados a essa tradição.

Além da devoção a Nossa Senhora do Rosário o Congado da APAE-OP também tem devoção a Nossa Senhora das Graças que já era considerada padroeira da APAE-OP contando, inclusive, com uma capela para essa santa dentro das dependências da escola ${ }^{3}$. Essa não é uma santa tradicionalmente cultuada pelo congado, contudo, acompanhando o movimento singular de criação do Congado da APAE-OP, O grupo passou a ser designado a partir da devoção a santa tradicional do congado e a padroeira da instituição: Congado de Nossa Senhora do Rosário e Nossa Senhora das Graças.

O congado iniciado na Escola da APAE-OP foi inserido nos festejos em que a cultura congadeira se fazia presente. Esse contato favoreceu ao aprofundamento dos saberes e práticas sobre a manifestação da professora/capitã e também dos alunos/congadeiros. É o que constatamos na entrevista com João, que é um dos alunos membros do grupo:

A gente aprende a ter compromisso, saber tratar as pessoas, é verdade, viu? Tem a questão dos grupos diferentes, uns usam saia, cores diferentes, uns têm o toque dançante igual à gente. Aqui no Alto da Cruz (bairro), agora tem um grupo de Moçambique, né? E a batida deles é mais forte, o nosso congado é mais festivo e a gente aprende sobre essas coisas. (Silva, 2017, p. 114)

Na mesma perceptiva segue o relato de Francisco, aluno que desempenha o papel de $2^{a}$ capitão da guarda: "A gente também canta, reza, participa de missa, viaja, tudo é muito bom, mas, o mais importante é Nossa Senhora do Rosário". (Silva, 2017, p. 112)

Portanto, na escola da APAE-OP, O congado começou como uma atividade pedagógica, uma manifestação lúdica que procurava valorizar a cultura de Ouro Preto, mas a importância da cultura congadeira na cidade e sua eficácia pedagógica junto aos alunos fizeram dessa experiência um projeto pedagógico que passou a envolver diferentes segmentos da escola. A experiência também deu origem a uma nova guarda de congado que passou a existir junto com as demais guardas da cidade 4 . A presença do Congado da APAE-OP nas festas tradicionais de Ouro Preto e de outras localidades passou a ser algo constante revelando a capacidade que tem essa manifestação cultural e religiosa de se renovar e de incluir diferentes elementos em sua tradição.

\footnotetext{
${ }^{3}$ A existência de uma capela no interior da escola é parte de uma complexa relação entre a religiosidade e as práticas educativas em Ouro Preto, onde é possível detectar um elevado nível de proselitismo religioso nos espaços escolares. Uma análise mais detida desse fenômeno pode ser vista em Santos, 2014a.

${ }^{4}$ Além da professora/capitã o grupo conta com quinze participantes com diferentes pertencimentos raciais. Três têm deficiência auditiva, os demais apresentam deficiências intelectuais ou dificuldades de aprendizagem, nenhum deles têm deficiências severas e nem físicas.
}

Fonseca, M. V., Silva, F. S. O congado vai para a escola e a escola vai para o congado 10 


\section{O Congado como Prática Pedagógica na Escola da APAE-OP}

Quando iniciamos nossa pesquisa tínhamos como hipótese que o aparecimento de um grupo de congado em uma escola estaria fundamentalmente vinculado à emergência da temática da diversidade cultural na educação. No início do século XXI, esse foi um movimento forte dentro da educação brasileira que, entre outras coisas, culminou no estabelecimento da Lei 10.639/03 que determinou a incorporação da cultura afrobrasileira e africana nas práticas pedagógicas das escolas.

A dinâmica do grupo de congado no interior da escola da APAE-OP e seu período de surgimento, no ano de 2002, eram indicações fortes em direção à hipótese de filiação dessa experiência às discussões sobre diversidade, porém, todo o processo de análise demonstrou as limitações dessa hipótese. O Congado da APAE-OP não está diretamente vinculado ao processo de emergência das questões relativas à educação das relações étnico raciais. Na verdade, trata-se de uma experiência única que revela a força e a vitalidade do próprio congado na cidade de Ouro Preto.

Quando investigamos no interior da escola as conexões entre o congado e a Lei 10.639/03 verificamos o distanciamento das práticas educativas dessa instituição com a temática da educação das relações étnico-raciais. Dentro da escola o congado não foi efetivamente tratado como subsídio para a compreensão de práticas culturais afrobrasileiras. Essa dimensão obteve avanços consistentes apenas em relação à professora Silvânia que, de forma ampla, incorporou esses elementos em sua prática pedagógica.

Em sua entrevista a professora Silvânia revelou que passou a ter uma intensa vivência dentro da cultura congadeira, aliás, isso passou a ser central em sua experiência de vida:

Olha, o congado, para mim, costumo falar que ele é um tudo, porque, através dele, eu consegui fazer com que minha fé aumentasse. Eu consegui resolver os meus problemas pessoais. Eu consegui, acho, que ver ou me aceitar em si. E na religião, até então, era um católico de "fajutagem", né? Falava que era católico, ia a missa uma vez na vida outra na morte, e olhe lá, aquele trem todo. Hoje não, eu aprendi a olhar para o céu e agradecer a Deus. Eu aprendi a fechar meus olhos e olhar para alguém e clamar à Virgem Maria. Então, o congado, para mim, é tudo, porque me ensinou, me devolveu a religiosidade. (Silva, 2017, p.142)

A experiência também modificou sua prática pedagógica:

Até então eu pensava que eu tinha que chegar lá, dar o meu dever do be-a-bá e pronto, acabou! Hoje, eu vi que não, você ensinar uma música para eles, aquilo ali está meu plano inteiro, não precisa preocupar em ensinar para eles a ler e escrever, isso aí é consequência, porque eu preciso fazer com que eles sejam sociáveis, que eles consigam adquirir a sociabilidade, eles verem que, qualquer coisa lá fora, qualquer coisa, se eles baterem isso aqui, vai estimular alguma coisa, vai servir de ensinamento para alguma coisa. Então, não tem precisão mais de eu ficar enchendo o caderno de plano, não tem. Qualquer prazer nos diverte. E eu atinei que se eu ensinasse para eles uma música do congado, eles iriam aprender o desenvolvimento da linguagem oral, da percepção auditiva, então são ' $N$ ' coisas que eu consigo. (Silva, 2017, p 145) 
O congado modificou a percepção da professora sobre sua religiosidade e também interferiu na sua prática pedagógica, inclusive, influenciando em sua formação acadêmica. Ela se formou no Curso de Pedagogia da Universidade Federal de Ouro Preto, em 2014, e elaborou como trabalho de conclusão de curso a monografia "As manifestações culturais como forma de letramento do deficiente intelectual". Nesse trabalho a professora Silvânia destacou o congado como elemento que pode ser visto como uma atividade educativa que interfere nos aspectos intelectuais e físicos dos educandos (Santos, 2014b).

No entanto, quando consideramos o conjunto dos educadores que compõe a escola da APAE-OP não encontramos a mesma experiência vivenciada pela professora Silvânia. Isso pode ser visto através do depoimento da professora de educação física que reconhece a dimensão pedagógica do congado, mas não o incorporou as suas aulas:

Olha, a questão do ritmo, tocar instrumentos, dentre outras coisas, podem ser trabalhados na Educação Física, porque é uma área que pode englobar tudo. Então, indiretamente, a gente já está trabalhando, mas não dou especificidade para o congado, como algo específico. (Silva, 2017, p.145)

Os profissionais vinculados à escola da APAE-OP se envolvem pouco com as experiências do congado na instituição. A participação mais ampla dos professores dáse, basicamente, no dia em que a guarda de congado promove uma festa na escola. Mas, no geral, todas as possibilidades pedagógicas que envolvem o Congado da APAEOP são pouco exploradas revelando uma limitação do processo de institucionalização da experiência no interior da instituição.

Na verdade, de forma muito semelhante aos educadores das escolas de todo o Brasil, o conjunto dos profissionais que compõe a escola da APAE-OP afirma que não possui uma formação específica para tratamento do tema relativo à Lei 10.639/03, demonstrando pouco conhecimento sobre o tema da educação e as questões ligadas às relações étnico-raciais.

Quando consideramos o conjunto dos educadores presentes na escola da APAE-OP constatamos que as justificativas relativas à presença do congado no contexto escolar foram elaboradas a partir de elementos que consideram pouco o reconhecimento da cultura negra e o combate à discriminação racial. A valorização do congado ocorre fundamentalmente a partir de aspectos que destacam a valorização da cultura local e também como uma atividade pedagógica que busca o conhecimento através do canto e da música como elementos capazes de promover um processo de socialização que interfere em aspectos físicos e intelectuais dos educandos.

Assim, o congado está situado dentro de uma perspectiva pedagógica que opera a partir de uma noção de flexibilização curricular que ocorre através diferentes projetos que são entendidos como capazes de atender às necessidades de alunos com

Fonseca, M. V., Silva, F. S. O congado vai para a escola e a escola vai para o congado 12 
deficiência. O congado é contabilizado como mais um desses projetos, como revelou uma das professoras da instituição:

Com certeza, se não fosse esses projetos, viu? Acho que toda escola tinha que ter essas coisas e, aqui, como oficina pedagógica, é o que ajuda e tá comprovado, né? A informática, esses recursos, o que acontece na aprendizagem, né? ... eu tento focar nisso, buscar jogos, algo que vai ajudar na aprendizagem, a alfabetizar... é o congado, coral de Libras, a Fanfarra. Olha para você ver, isso, com certeza, ajuda muito. Isso tudo já auxilia ele a concentrar, aprender a letra, a escrita, o cálculo. É muito bom, viu? (Silva, 2017, p. 81)

Esse relato indica que, em parte, o congado foi capturado pela lógica escolar que vê nele a possibilidade do desenvolvimento cognitivo e também de habilidades que são necessárias aos educandos. Contudo, mesmo diante dessas limitações que não permitiram a institucionalização plena do congado dentro do trabalho pedagógico desenvolvido na escola essa experiência se tornou uma atividade regular dentro da escola APAE-OP, permanecendo ativa desde ano de 2002 até os dias atuais.

\section{Considerações finais}

No Brasil, encontramos uma resistência em relação ao processo de incorporação da cultura negra como parte das atividades pedagógicas desenvolvidas no conjunto das escolas. Em Ouro Preto, essa realidade se manifesta sobretudo através do congado que, de um lado, é importante na dinâmica cultural da cidade, contudo se faz pouco presente nas atividades desenvolvidas dentro do conjunto de escolas da cidade. Santos (2019) realizou uma pesquisa nas escolas públicas de Ouro Preto para avaliar o tratamento que conferiam ao congado como uma das manifestações religiosas que se faziam presentes na cidade, sobretudo a partir da figura de Chico Rei que é um mitofundador dessa experiência. Segundo ela, o tema é pouco presente nas escolas contando inclusive com a dissociação da figura de Chico Rei das práticas religiosas do congado:

Em uma cidade histórica como Ouro Preto, onde a presença do Congado é latente e carrega o título de origem dessa manifestação afro-mineira pelo mito de Chico Rei, não valorizar essas questões em sala de aula proporciona a anulação desses conhecimentos. A escola, portanto, estaria negando a existência do mito de Chico Rei e do Congado na cidade de Ouro Preto por deixá-los à margem dos conteúdos possíveis e legitimados ao serem introduzidos e apresentados nas escolas. (Santos, 2019, p. 195)

A ausência de legitimidade produzida pela escola em relação à cultura e os saberes produzidos pela população negra é uma realidade que encontramos em Ouro Preto. Em face a essa realidade merece destaque a experiência que ocorre com o congado na escola da APAE-OP na qual não encontramos paralelo nas demais escolas públicas da cidade.

Pode ser que o fato de ser uma escola de educação especial tenha favorecido para que ocorresse uma aproximação entre suas atividades pedagógicas e o congado. No

13 - Linhas Críticas, Brasília, DF, v. 26 (2020), p. 13-16 
entanto, essa não foi uma das questões que norteou nossa investigação e nem tampouco trata-se de algo que descaracteriza a importância dessa experiência em que - congado foi capaz de transpor as barreiras tradicionalmente encontradas na educação brasileira.

Na verdade, o Congado de Nossa Senhora do Rosário e Nossa Senhora das Graças revela uma dimensão inclusiva da cultura congadeira que foi capaz de incorporar no interior de sua tradição uma experiência que foi construída a partir de uma atividade pedagógica.

Essa dimensão inclusiva torna-se ainda mais ampla quando consideramos que se trata de crianças e jovens com deficiência que foram plenamente incorporadas às manifestações e aos ritos da cultura congadeira. É o que registra a professora Silvânia em relação às viagens para participação do grupo nas diferentes festas de devoção a Nossa Senhora do Rosário, nas quais ocorre o encontro e a interação com outras guardas de congado:

Os meninos são especiais, tem que ter mais atenção com eles, né?... Não tem nada de difícil para mim. Atenção, temos que ter com todos, meus meninos são ótimos, realmente são especiais. $E$, no congado, não há diferença, todos são iguais, tendo objetivo de louvar Nossa Senhora... na guarda de Congo, não temos excepcionais, temos congadeiros, assim, eles devem ser vistos e entendidos. (Silva, 2017, p. 114)

O congado é uma prática cultural e religiosa que foi fundamental dentro do processo de afirmação da cultura negra no Brasil. Ele se estruturou como elemento de devoção e de resistência da população negra que teve que enfrentar fortes preconceitos para manter viva suas tradições culturais e religiosas. Nesse sentido, revela-se como uma prática social que traz dentro de si elementos que estão ligados à inclusão, sobretudo na sua capacidade de incorporação e reconhecimento do outro.

A experiência da escola da APAE-OP é uma manifestação clara do poder de inclusão do congado e das possibilidades pedagógicas que envolvem suas diferentes dimensões. Isso fica evidente mesmo quando consideramos dentro da experiência que tratamos as limitações em relação a uma proposta de educação das relações raciais, inclusive como forma de combate à discriminação racial e religiosa. Contudo, podemos dizer que o Congado de Nossa Senhora do Rosário e de Nossa Senhora das Graças representa uma dinâmica única e surpreendente que sinaliza para as diferentes possibilidades de relação entre a cultura escolar e a cultura negra.

Uma experiência dessa natureza é própria de uma cidade como Ouro Preto onde a cultura negra se manifesta com força e uma enorme capacidade de renovação e revigoramento. Portanto, é nessa cidade que se tornou um dos locais mais expressivos de manifestação da cultura negra que encontramos uma experiência única onde o congado vai para a escola e a escola vai para o congado!

Fonseca, M. V., Silva, F. S. O congado vai para a escola e a escola vai para o congado 14 


\section{Referências}

Alves, V. de F. N. (2017). Rastros de África no Brasil: práticas educativas no reinado de Nossa Senhora do Rosário. Mazza Ediç̄ões.

Associação de Pais e Amigos dos Excepcionais de Ouro Preto (APAE-OP). (1982). Livro de Ata da Assembleia de Constituição da APAE-OP. APAE-OP.

Associação de Pais e Amigos dos Excepcionais de Ouro Preto (APAE-OP). (2012). Estatuto da APAE-OP. APAE-OP.

Associação de Pais e Amigos dos Excepcionais de Ouro Preto (APAE-OP). (2008). Projeto

Político Pedagógico APAE-OP - 2008/2013. APAE-OP.

Borges, C. M. (2005). Escravos e libertos nas Irmandades do Rosário: devoção e solidariedade em Minas Gerais: séculos XVIII e XIX. Editora da UFJF.

Federação Nacional dos Pais e Amigos dos Excepcionais (FENAPAES). (2017).

Posicionamento do movimento apaeano em defesa da inclusão escolar de pessoas com deficiências intelectual e múltipla. FENAPAES.

Gomes, N. P. M., \& Pereira E. A. (2003). Ouro Preto da Palavra. Editora da PUC MINAS.

Lüdke, M., \& André, M. E. D. A. (1986). Pesquisa em educação: abordagens qualitativas.

EPU.

Martins, S. (1991). Folclore brasileiro: Minas Gerais (2. ed.). Editora da UFMG.

Mazzota, M. J. da S. (1996). Educação Especial no Brasil: história e políticas públicas. Cortez.

Santos, A. M. dos. (2019). O Grande Anganga Muquixe Chico Rei: a presença do mito negro no Reinado do Alto da Cruz e nas escolas de Ouro Preto/MG. [Dissertação de mestrado, Universidade Federal de Ouro Preto]. Repositório institucional da UFOP. https://www.repositorio.ufop.br/handle/123456789/11740

Santos, G. A. (2014a). Encontros de ensino religioso nas cidades de Ouro Preto e Mariana: a laicidade da educação pública em questão. [Dissertação de mestrado, Universidade Federal de Ouro Preto]. Repositório Institucional da UFOP. https://repositorio.ufop.br/handle/123456789/4176

Santos, S. A. (2014b). As manifestações culturais como forma de letramento do deficiente intelectuais. (Monografia Curso de Pedagogia). Centro de Educação Aberta e a Distância, Universidade Federal de Ouro Preto.

Silva, F. S. (2017). O congado na experiência Escolar da APAE de Ouro Preto: um estudo de caso sobre a cultura congadeira no contexto da educação especial. [Dissertação de mestrado, Universidade Federal de Ouro Preto]. Repositório Institucional da UFOP. https://www.repositorio.ufop.br/handle/123456789/9237 


\section{Biografia}

\section{Marcus Vinícius Fonseca}

Mestre em Educação pela Universidade Federal de Minas Gerais (UFMG), Doutor em Educação pela Universidade de São Paulo (USP), Professor Associado da Universidade Federal de Ouro Preto (UFOP), onde atua no Departamento de Educação e no Programa de Pós-graduação em Educação, Coordenador do Grupo de Pesquisa GERAES - História e Historiografia da Educação/UFOP.

E-mail: mvfonseca2@yahoo.com.br

ORCID: http://orcid.org/0000-0003-0127-5009

\section{Fabiana Siqueira Silva}

Graduação em geografia pelo Instituto Federal de Educação de Minas Gerais (IFMG), Mestre em Educação pela Universidade Federal de Ouro Preto (UFOP).

E-mail: fabiana.siqueirasilva@yahoo.com.br

ORCID: http://orcid.org/0000-0003-3450-0663

\section{(c) ()}

Licença Creative Commons. Este trabalho está licenciado sob uma Licença Internacional Creative Commons Attribution 4.0. 